\title{
O PROCESSO DE CUIDAR DE ENFERMAGEM AO PORTADOR DE DOENÇA CRÔNICA CARDÍACA
}

\author{
Nursing care plan for patients with chronic heart disease \\ Proceso de cuidados de enfermería al paciente con insuficiencia \\ cardiaca crónica.
}

\author{
Anice de Fátima Ahmad Balduino ${ }^{1}$
}

Maria de Fátima Mantovani

Maria Ribeiro Lacerda ${ }^{3}$

\section{RESUMO}

Estudo de natureza qualitativa exploratória, realizada em hospital de ensino de Curitiba, cujos objetivos foram: identificar o processo de cuidar ao portador de doença crônica cardíaca e descrever os seus elementos. Constituíram sujeitos do estudo oito enfermeiros. A coleta de dados realizou-se por meio de entrevista semiestruturada, seguida da análise de seus conteúdos. Verificou-se que os enfermeiros, durante a visita diária, desenvolvem o processo de cuidar por meio de ações e dimensões técnicas e expressivas. Outro aspecto relevante sobre a prática de cuidar é que o enfermeiro está consciente da necessidade de um corpo de conhecimento próprio para cada especialidade, que o sustenta em suas ações de julgamento clínico para a tomada de decisões, assim como orienta os membros da equipe de enfermagem. Salientou-se que o processo de cuidar propicia a promoção da saúde direcionada à qualidade de vida dos pacientes.

Palavras-chave: Cuidados de Enfermagem. Promoção da Saúde. Doença Crônica.

\begin{abstract}
The present study is a qualitative and explorative analysis that took place in the Teaching Hospital in Curitiba. The main objective is to identify the nursing care plan for patients with chronic heart failure followed by the analysis of its contents. Eight nurses were chosen to participate in this study. The data collection was obtained using semi-structured interviews followed by the analysis of their contents. We observed that during the nurses' daily visit they developed the care process through expressive actions and technical dimensions. Another relevant aspect about the practice of health care is that the nurse is aware of the need to master a deep knowledge of each specialty. This will support the nurse's clinical trial process, ensuring the correct decisions are being made, according to orientation from the nursing team. We want to highlight that the nursing care process provides better health standards targeted to promote a better quality of life for the patients.
\end{abstract}

Keywords: Nursing Care. Health Promotion. Chronic Disease.

\section{Resumen}

El presente trabajo es una investigación de tipo cualitativo que se llevó a cabo en el Hospital de Enseñanza de Curitiba. El objetivo principal del mismo es identificar el proceso de acompañamiento y cuidados de los pacientes que sufren de insuficiencia cardiaca crónica y hacer una descripción de los elementos que conforman este proceso. Un grupo de ocho enfermeros participó en este estudio. La metodología de recolección de datos se realizó a través de entrevistas semiestructuradas, seguidas del análisis de la información obtenida. Se verificó que durante la visita diaria, los enfermeros desarrollaron el proceso de acompañamiento y cuidados valiéndose de acciones que envolvían tanto el conocimiento técnico como el lenguaje expresivo. Otro aspecto relevante que envuelve la práctica de cuidar - es que el enfermero está plenamente consciente de la necesidad de contar con un cuerpo de conocimientos específicos de cada especialidad que va a sustentar su capacidad de juicio clínico durante la tomada de decisiones, según las orientaciones de los miembros del equipo de enfermeros. También subrayamos que el acompañamiento y cuidados promueven la salud y son dirigidos a mejorar la cualidad de vida de los pacientes.

Palabras clave: Atención de enfermería. Promoción de la salud. Enfermedad crónica.

\footnotetext{
'Enfermeira, Mestre em Enfermagem, Universidade Federal do Paraná, Brasil. Membro do Grupo de Estudos Multidisciplinar Saúde do Adulto - GEMSA. Brasil. E-mail: anicebalduino@ig.com.br, ${ }^{2}$ Profa Doutora em Enfermagem da Universidade Federal do Paraná, Brasil. Coordenadora do GEMSA e vice-coordenadora da Pós-Graduação de Mestrado em Enfermagem.Brasil. E-mail: mantovan@ufpr.br, ${ }^{3}$ Prof ${ }^{a}$ Doutora em Enfermagem da Universidade Federal do Paraná, Brasil. Coordenadora da Pós-Graduação de Mestrado em Enfermagem e do Núcleo de Estudo e Extensão em Cuidado Humano de Enfermagem - NEPECHE. Brasil. E-mail: lacerda@milenio.com.br
} 


\section{INTRODUCÃO}

0 cuidado faz parte da vida do ser humano desde os primórdios da humanidade, como resposta ao atendimento às suas necessidades. Para realizar o cuidado, o enfermeiro, como membro integrante da equipe multidisciplinar, utiliza um conjunto de conhecimentos que possibilita a busca de resolutividade às respostas dos fenômenos de saúde, definidos pelo Internacional Council of Nurses ${ }^{1}$ como aspectos de saúde relevantes à prática de Enfermagem.

0 instrumento para a realização do cuidado é o processo de cuidar ${ }^{2}$, mediante uma ação interativa entre o enfermeiro e o paciente. Nele, as atividades do profissional são desenvolvidas "para" e "com" o paciente, ancoradas no conhecimento científico, habilidade, intuição, pensamento crítico e criatividade e acompanhadas de comportamentos e atitudes de cuidar/ cuidado no sentido de promover, manter e/ou recuperar a totalidade e a dignidade humana.

0 desenvolvimento do cuidado ocorre nas suas mais diferentes especialidades e, neste estudo, abordará o processo de cuidar ao paciente crônico cardíaco.

0 paciente adulto crônico cardíaco apresenta comprometimento de seu todo harmônico, seu estado de saúde está alterado, pois começa a sentir que a força física e a força do coração estão diminuídas. Surge a aterosclerose nos vasos sanguíneos, ocorre a perda do tecido ósseo, e há carência na autoestima ${ }^{3}$. Nessa fase, o doente pode apresentar limitações emocionais, financeiras, perdas pessoais e sociais e precisará aprender a administrar o seu tratamento efetivo. Nessas circunstâncias, quando ele se encontra fragilizado, é que 0 enfermeiro assume um papel importante e muito expressivo para com ele, no sentido de ajudá-lo não só a enfrentar as dificuldades em torno da doença, mas também de cuidá-lo nas suas necessidades de segurança, carinho e autoconfiança. Desse modo, é importante que o enfermeiro compreenda que os pacientes portadores de doença crônica requerem, do profissional, um raciocínio clínico e crítico constante, pois uma simples preocupação que apresentem pode colocar em risco suas vidas.

0 enfermeiro tem uma função fundamental na equipe de saúde, já que, por meio da avaliação clínica diária do paciente, poderá realizar o levantamento dos vários fenômenos, seja na aparência externa ou na subjetividade da multidimensionalidade do ser humano. Igualmente poderá providenciar para que 0 paciente seja atendido nos mais diferentes segmentos da equipe de saúde e/ou de enfermagem.

A Organização Mundial de Saúde, em seu documento "Cuidados inovadores para as condições crônicas", enfatiza que o paciente portador de doença crônica carece de cuidados planejados, capazes de prever suas necessidades básicas e proporcionar atenção integrada. Essa atenção envolve tempo, cenário da saúde e cuidadores, além de treinamentos para que o paciente aprenda a cuidar de si mesmo em sua residência. 0 paciente e seus familiares precisam de suporte, de apoio para a prevenção ou administração eficaz dos eventos crônicos ${ }^{4}$

Diante do exposto, optou-se por investigar como os enfermeiros conduzem a prática de cuidar ao portador de doença crônica cardíaca, a partir da composição de seu método de cuidar. Para atender esse questionamento, os objetivos da pesquisa foram: identificar os elementos do processo de cuidar realizado pelo enfermeiro ao portador de doença crônica cardíaca e descrever os elementos evidenciados no processo de cuidar em enfermagem ao portador de doença crônica cardíaca.

\section{MÉTODO}

Este estudo foi de natureza qualitativa, na modalidade exploratória. A investigação realizou-se no Serviço de Cardiologia de atendimento clínico ao portador de doença crônica e no Serviço de Internação Clínica Médica do hospital de ensino. Os sujeitos da pesquisa se constituíram de oito enfermeiros: sete assistenciais e um gerente de unidade funcional, que trabalham nesses serviços. A coleta de dados realizou-se por meio da entrevista semiestruturada e gravada. 0 instrumento foi previamente testado e solicitava dados de identificação do sujeito, como, sexo, tempo de formado, tempo que trabalhava com doentes crônicos e crônicos cardíacos, além de três questões referentes ao processo de cuidar. As entrevistas foram realizadas individualmente nos meses de fevereiro, março e abril de 2007, em locais de trabalho, em uma sala reservada, o que permitiu privacidade aos sujeitos para se expressarem com tranquilidade e segurança.

0 período de duração das entrevistas foi, em média, de uma hora e trinta minutos. Foram gravadas em MP3 player digital USB-831 e, posteriormente, transferidas para hardware e transcritas na íntegra. A análise das informações foi feita mediante a descrição das categorias definidas segundo Conteúdo de Bardin ${ }^{5} .0$ objetivo principal da análise de conteúdos é 0 tratamento das mensagens tomadas em consideração, que mostram os indicadores, possibilitando inferir sobre outra realidade que não a da mensagem ${ }^{5}$. Foram respeitados os aspectos éticos definidos na Resolução 196/96 sobre a pesquisa com seres humanos. Dessa forma, o projeto foi aprovado pelo comitê de ética em pesquisa da instituição, $n^{0}$ 1288.136/200609.

\section{APRESENTAÇ̃̃O E DISCUSSÃO DOS RESULTADOS}

Dos oito enfermeiros participantes desta pesquisa, 87,5\% eram do sexo feminino e $12,5 \%$ do sexo masculino; o tempo de formação variou entre 10 (no mínimo) e 29 anos (no máximo), com uma média de 19 anos e 5 meses. Em relação ao tempo médio de trabalho, este foi de 22 anos; e quanto ao tempo médio de trabalho dos enfermeiros que cuidam de pacientes crônicos cardíacos, existe uma amplitude de 1 mês a 34 anos, com uma média de 10 anos e 5 meses. 
A partir da organização e análise do conteúdo das entrevistas, foram identificadas três categorias e nove subcategorias que deram significados ao processo de cuidar do enfermeiro ao portador de doença crônica cardíaca, os quais são apresentados a seguir.

\section{O CUIDAR}

0 cuidar é oferecido aos pacientes crônicos cardíacos mediante ações, emoções e sensibilidade que 0 ajudem a vivenciar o processo de adoecimento. Assim, estabeleceram-se duas subcategorias: dimensão técnica e dimensão expressiva.

\section{Dimensão técnica}

Ao cuidar do paciente, o enfermeiro procura estar atento às alteraçõ̃es emergenciais.

A nivel hospitalar [...] o cuidar atenta a sinais e sintomas daquilo que eu possa fazer para evitar que o paciente apresente um problema cardíaco mais sério[...]. (E1)

Ocuidaréo ato em que você dá assistência, procura fazer a parte científica desses cuidados; o cuidar é o cuidado, é a execução daquela ação. (E5)

A avaliar o quadro dele, qual é o atendimento no quadro dele de momento. Um paciente cardíaco que está na cama, então já está com oxigênio, está com um quadro mais agudo ou mais grave; ver o cuidado com oxigênio, verificar a pressão dele é de quantas horas [...] olhar a unha para ver se a circulação está boa ou não, se está cianótico. (E3)

No depoimento do enfermeiro, verifica-se a noção de cuidar como atenção aos sinais, sintomas e complicações do adoecimento, bem como da terapêutica empregada. Nessa visão, o profissional tem conhecimento adequado dos princípios fisiológicos básicos que regem o funcionamento do sistema cardiocirculatório ${ }^{6}$. Os relatos evidenciam que 0 enfermeiro realiza o cuidar na execução das ações de enfermagem a pacientes com doença crônica cardíaca por meio de procedimentos técnicos, como observar sinais e sintomas a fim de evitar que o paciente apresente evolução para um quadro de complicações. Precisa saber identificá-los para manter o paciente estável, permitindo-lhe aguardar para realizar, se for o caso, um possível procedimento cirúrgico, um exame diagnóstico terapêutico ou até um procedimento intervencionista.

A dimensão técnica ou instrumental é caracterizada pelas ações físicas desempenhadas, relacionadas aos papéis que cumprem expectativas sociais. Incluem processos de cuidar, permeados por saberes e fazeres, que são orientados em longo prazo ${ }^{7}$.

\section{Dimensão expressiva}

A dimensão expressiva refere-se a estar próximo ao paciente, respeitá-lo, assisti-lo na sua integralidade de maneira humanizada. 0 enfermeiro deve estar atento aos fenômenos relevantes à prática de enfermagem, ao diagnóstico médico e à elaboração da prescrição de enfermagem, como é observado nos depoimentos a seguir:

Para mim o cuidar é estar próximo do paciente, levantar os problemas de enfermagem, diagnóstico médico, problema do paciente. Eu posso fazer levantamento de todos, fazer uma prescrição de enfermagem, do cuidar dentro daquele que apresenta no momento. [...] 0 cuidar está nisso também, a questão social [...] você conhece o paciente, o acompanhante, a gente libera 0 acompanhante dentro das normas, esse é outro lado do cuidado, no meu ponto de vista ajuda muito, então esse é o cuidado, [...]. É o contato direto. (E1)

Todo cuidado dispensado ao paciente durante sua internação, priorizando suas necessidades básicas. A gente tem que verificar o estado do paciente, como ele interna, qual o primeiro cuidado que vai serfeito. (E7)

Dedicação, amor, técnica, pesquisa, eficiência voltados ao cuidar bem daquele ser humano, que precisa de outro ser humano, porém este com treinamento e capacidade para tal assistência. (E2)

Para o enfermeiro, o cuidar é entendido como aplicação de conhecimentos científicos no cotidiano associados à habilidade de utilizar a emoção e a sensibilidade como bases da comunicação para executar cuidados de enfermagem, respeitando o paciente como um ser humano ${ }^{8}$. Tal postura pode ser confirmada na afirmação de E2.

É possível observar que o cuidar humanizado torna-se indispensável ao enfermeiro, que deve ir além do estudo de caso e tratar o paciente não como um mero objeto do processo de cuidar, visto que, como profissional, precisa transcender o cuidado propriamente dito, apresentar a capacidade de compreensão de quem é esse paciente, o que o levou ter a doença. A implementação das ações do cuidado no dia-a-dia do enfermeiro implica, também, perceber o paciente como um ser total, respeitar seus valores, crenças, sentimentos, emoções, e não apenas considerar o aspecto biológico. Para os enfermeiros que participaram desta pesquisa, o cuidar, na dimensão expressiva, é considerado um ato de amor e dedicação. Isso pode ser verificado nas situações expressas a seguir: 
[...] eu não posso tratá-lo como um mero estudo de caso, um mero objeto, tem que ir mais além de levantar os dados, as necessidades básicas. Ele tem que ir mais além, ele tem que transcender o processo de cuidar, ele tem que ver quem é esse indivíduo que está hoje na sociedade, qual é a condição dele, o que o levou a essa doença exatamente, para que eu possa também ter uma referência de como orientá-lo, como acalmá-lo. (E2)

0 depoimento de $\mathrm{E} 2$ confirma o que Horta ${ }^{9}$ preconiza, pois transcender 0 assistir nas necessidades básicas do ser humano é ir além da obrigação, é estar comprometido, engajado na profissão, é compartilhar a experiência vivenciada com cada ser humano sob seus cuidados. É usar-se terapeuticamente, é doar calor humano, é envolver-se e viver cada momento como o mais impor tante da profissão.

Neste estudo fica evidente que tanto a dimensão técnica como a expressiva do cuidar não se realizam como um ato isolado. Requerem do enfermeiro preocupação, responsabilidade, expertise, sensibilidade, solidariedade e interação/vínculo com os pacientes portadores de doença crônica cardíaca. Ambas propõem um cuidado humano integral que considere o paciente como ser individual e único. Essas duas vertentes do cuidar não acontecem isoladamente, mas dependem do instante em que o enfermeiro e o paciente se encontram, e uma prevalece com maior intensidade sobre a outra $^{10}$.

\section{PRÁTICA DO CUIDAR/ CUIDADO}

A prática do cuidar/cuidado, na perspectiva dos enfermeiros participantes deste estudo, significa manter proximidade e tornar individual o cuidado para com o paciente portador de doença crônica cardíaca com responsabilidade e um corpo de conhecimento próprio de Enfermagem e de outras ciências. Assim, emergiram duas subcategorias denominadas concepções de ser humano e concepções de enfermagem.

\section{Concepções de ser humano}

Nas concepções de ser humano destacam-se alguns aspectos, como: ser complexo com necessidades básicas; ser projetado por Deus; criatura; ser pensante; doente crônico cardíaco. 0 ser complexo com necessidades básicas é aquele que precisa de cuidado, atenção e respeito com o seu corpo físico. É o que requer equilíbrio quanto aos fatores psicoemocionais, satisfação de suas necessidades básicas “ fisiológica e autorrealização " e respeito como cidadão, conforme se observa a seguir:

Ser complexo com necessidades básicas, [...] tentar se equilibrar dentro da sociedade. Ser um cidadão que têm direitos e deveres. (E1)
Ser humano para mim é ser gente e tratar todos com amor carinho e respeito e ter pessoas como seus semelhantes e saber que em quaisquer condições que se encontra uma pessoa, amanhã poderá ser você. [...] éo dotado de sentimento, de inteligência, de capacidade de resolver problema, de tomar decisão. (E3)

Um ser que pensa, tem vida própria, costumes, crenças, estilo de vida que deve ser respeitado. (E4)

O ser humano na visão nightingaleana constitui-se de corpo e mente, originando um ser de harmonia e, ao cuidar de sua saúde, visa à totalidade ${ }^{11} .0$ ser humano tem necessidades psicobiologias, psicoespirituais e psicossociais que estão relacionadas e são comuns a todos eles, variam na sua manifestação e na maneira de satisfazê-las ou atendê-las ${ }^{9}$.

Para os participantes, esse ser é projetado por Deus, uma obra "divina", a mais bem projetada e elaborada pelo criador do universo. Essa criatura é formada pelo corpo físico, psicológico, pelas emoções e pela alma, diferenciada pelo sexo, idade e cultura. Diante disso, quando o enfermeiro cuida desse ser humano, deve fazê-lo com amor, carinho e respeito, uma vez que são semelhantes. As falas a seguir ilustram essa prática do cuidar/cuidado:

[...] a mais bem projetada obra e elaborada pelo criador do universo, Deus, uma criatura "divina", não há ninguém diferente de mim. [...] Quando o profissional vai cuidar dessa pessoa deve inserir amor no seu cuidado, tem sempre que olhar o outro como igual a você, que está em suas mãos por obra e graça do próprio Deus, então vamos cuidar com carinho, vamos cuidar com amor. (E2)

[...] não somos todos iguais, cada um tem a sua diferença individual, mas somos semelhantes, que o próprio Deus disse [...]. (E3)

Na perspectiva do enfermeiro, o portador de problemas cardiológicos irreversíveis necessita de cuidados de enfermagem, tratamento contínuo e consultas médicas periódicas, como pode se constatar nas falas a seguir:

Éo ser humano que necessita de assistência médica e de enfermagem devido a um agravo físico permanente do sistema cardiovascular. (E2) Paciente que tem sofrimento pela patologia, que faz tratamento continuado e consulta periódica. (E3) 
Pacientes que têm um diagnóstico de patologia, cardíaca e se reinternam várias vezes para compensação do quadro clínico. (E7)

A doença crônica cardíaca desenvolve-se com o tempo e, na maioria das vezes, é o resultado de uma incapacidade crescente de compensar os mecanismos fisiológicos. Verifica-se que 0 enfermeiro entende a gravidade e as consequências da doença e percebe o sofrimento do doente crônico quando ocorrem constantes internações e há aumento das complicações.

\section{Concepções de enfermagem}

Nas concepções de enfermagem destacam-se algumas perspectivas como: profissão, categoria profissional, equipe, ciência e arte, conhecimentos específicos organizados e sistematizados e ações baseadas nas necessidades do portador de doença cardíaca. A profissão é entendida como dotada de obrigações, direitos e responsabilidades, pois cuida da vida de seres humanos desde o nascimento até a morte. Um erro do profissional poderá ser fatal para o ser humano; portanto, responsabilidade e competência são fundamentais a essa profissão. 0 enfermeiro precisa estar vinculado ao órgão de classe que regulariza a profissão e respeitar seu Código de Ética. Essas considerações são observadas nos depoimentos a seguir:

[...] o profissional tem que estar vinculado a um órgão superior que legaliza essa profissão, é um grupo de gente capacitada, formada, que cuida de outras pessoas, são profissionais, é uma profissão.

É uma profissão como outra qualquer, dotada de obrigação, direito e responsabilidade, com um diferencial, que se trata de cuidar de vida, um erro pode ser fatal, isso aumenta a responsabilidade profissional. (E3)

A perspectiva categoria profissional, para os sujeitos, caracteriza-se pelo conjunto dos profissionais de enfermagem que, com enfermeiros, técnicos e auxiliares de enfermagem, constitui-se numa equipe que desenvolve ações e presta cuidados profissionais a pacientes/clientes, famílias e comunidades. É importante que o enfermeiro conheça a legislação específica da profissão, já que desenvolve as ações de cuidar, direta ou indiretamente, e procura atender aos fenômenos relevantes à prática de enfermagem necessária ao paciente crônico cardíaco. Os depoimentos que seguem reafirmam esse conhecimento.

Éum grupo de profissionais tecnicamente capazes inseridos para prestar cuidado profissional. (E2)
[...] enfermeiro, auxiliar, técnico, um ser humano, que estudou para cuidar do outro ser humano [...]. (E7)

Nesse aspecto, cabe ressaltar o Decreto $n^{0} 94.406 / 87$ que regulamenta a Lei $n^{0} 7.498$, de 25 de junho de 1986 e dispõe sobre a regulamentação do exercício profissional, definindo o papel de cada membro da equipe de enfermagem ${ }^{12}$. $\mathrm{Na}$ fala de E2, percebe-se que a habilidade técnica e 0 conhecimento teórico se agrupam à cientificidade do fazer profissional e geram o cuidado profissional ${ }^{13}$.

A Enfermagem é considerada a maior força de trabalho em cuidados à saúde. É um grupo de profissionais bem distribuídos e que têm vários papéis, funções e responsabilidades. Os enfermeiros propiciam cuidados aos seres humanos, às famílias e comunidades quando promovem a saúde, previnem doenças, tratam e reabilitam seres pessoas 9 .

No que se refere à ciência e arte, a Enfermagem é evidenciada dentro de suas diferentes especialidades, e, em sua prática, o enfermeiro é o gerenciador e moderador do cuidado. Isso pode ser demonstrado a seguir:

[...] a Enfermagem é uma especialidade, baseiase na ciência, na prática da assistência desenvolvida pela pesquisa, cada profissional desenvolve-se dentro da sua capacidade, de sua hierarquia e cada um dentro do seu desenvolvimento [...]. (E2)

\section{[...] Enfermagem tem que ter embasamento científico, não faz nada por fazer, para desenvolver ações do cuidado ao paciente [...]. (E7)}

Observa-se que os enfermeiros não definiram a Enfermagem segundo Horta:29, como a ciência e a arte de assistir o ser humano no atendimento de suas necessidades básicas, de torná-lo independente desta assistência, quando possível, pelo ensino do autocuidado, de recuperar, manter e promover a saúde em colaboração com outros profissionais. Eles a caracterizaram como uma especialidade que busca conhecimentos específicos, organizados e sistematizados em teorias e modelos de estrutura, que visa descrever, explicar e predizer fenômenos relevantes à disciplina de Enfermagem ${ }^{14}$, aspecto evidenciado pelos enfermeiros do estudo nas entrevistas E2 e E7.

Como arte, a Enfermagem é uma forma de expressão cultural, de comunicação que expressa sentimentos. Ao realizar o cuidar e ao se relacionar com o outro, dispõe-se a conhecer e a vivenciar os sentimentos 2 , como afirma $E 7$ em "não faz nada porfazer".

Ainda, o aspecto ações de enfermagem, baseadas nas necessidades do paciente, é aquele que ocorre durante a hospitalização do paciente com doença crônica cardíaca. É o momento em que ele deve receber todo o cuidado e ter 
preservadas suas necessidades básicas, como as fisiológicas, de segurança, sociais, de afeto e autoestima, para que tenha um internamento sem intercorrências psicossoais, aspectos mencionados pelos sujeitos do estudo na seguinte fala.

O cuidado dispensado ao paciente durante sua internação, sempre preservando as necessidades básicas do mesmo. Tem que se inteirar de tudo, se está recebendo os cuidados que ele precisa no momento. (E7)

\section{Oprocesso de cuidar para mim vai desde o momento que o paciente se interna, até que você descobre que ele é cardíaco, muito tempo no internamento, até a pós-alta. (E3)}

Outro aspecto que se destaca na perspectiva das ações baseadas na necessidade do paciente, é a tomada de decisão do enfermeiro quanto ao momento de liberar o paciente para cuidar-se. Essa atitude do enfermeiro contribui para que 0 paciente tenha uma melhor aceitabilidade, confiabilidade e adesão ao tratamento, não retornando com maior frequência aos internamentos. Essas ações são mencionadas no depoimento:

É avaliar, verificar a real necessidade dele, tem que ver a realidade daquele paciente, uma hora que ele precisar fazer por si, eu acho que o cuidar está no processo de cuidar. (E8)

Na subcategoria concepção de ser humano, constata-se que os enfermeiros vivenciam o processo de cuidar por meio das seguintes ações: estar presente, dar mais atenção, interagir, prestar orientações para que o paciente crônico cardíaco se autocuide, e avaliar as condições do paciente tanto no aspecto biológico quanto no aspecto emocional. Na subcategoria concepções de Enfermagem, percebe-se a importância que o enfermeiro confere ao fato de fazer com que as pesquisas sejam aplicadas no seu cotidiano. Com isso, os resultados efetivos de suas ações podem contribuir para um avanço técnico-científico na Enfermagem. Esse entendimento corrobora o preconizado por Horta' ${ }^{9}$ pois uma das funções do enfermeiro na área específica é assistir o ser humano em suas necessidades básicas e ensinar-lhe o autocuidado.

\section{PROMOÇÃO DA SAÚDE}

A categoria promoção da saúde tem sido, mundialmente, foco de atenção dos profissionais da saúde, em consequência da predominância das doenças não-transmissíveis, principalmente das doenças cardiovasculares, por oferecer a esses doentes possibilidades transformadoras em seus hábitos de vida. Essa categoria é considerada como um mecanismo de fortalecimento e implantação de uma política transversal, integrada e intersetorial, que faz dialogar as diversas áreas do setor sanitário, os outros setores do Governo, o setor privado e não-governamental e a sociedade, compondo redes de compromisso e corresponsabilidade quanto à qualidade de vida da população em que todos sejam partícipes na proteção e no cuidado com a vida ${ }^{15: 12}$

Neste estudo, os enfermeiros referem-se à categoria promoção à saúde como o preparo do paciente para a qualidade de vida, a qual foi dividido em cinco subcategorias: educação à saúde, orientação, concepção de saúde, concepção de doença crônica cardíaca e ambiente.

Nas falas descritas pelos enfermeiros, existe uma inferência significativa da palavra "orientação", que pode ser entendida sob duas circunstâncias. A primeira é educação à saúde, na qual o enfermeiro conhece o paciente crônico cardíaco, mediante a troca de informações entre paciente e família. Nesse processo, há o respeito pelas crenças e valores dos envolvidos no contexto. A segunda situação é a orientação propriamente dita, em que se transmitem informações para o ser cuidado e seus familiares. Portanto, essas subcategorias serão apresentadas a seguir:

\section{Educação à Saúde}

A educação à saúde vai além do cuidar imediato, estendendose à educação que promove o desenvolvimento do conhecimento, mediante apreensão e busca das modificações/transformações nos hábitos de saúde ao portador de doença crônica cardíaca, proporcionando-lhe qualidade de vida. 0 enfermeiro procura desenvolver ações para a saúde do paciente de forma lúdica para que o emocional esteja em sincronia com a dimensão física. Desse modo, também propicia às famílias condições para que sejam coadjuvantes não só na prevenção e na manutenção, mas também na reabilitação desses pacientes. Os depoimentos exemplificam essas situações:

[...] a educação e orientações preventivas, que busquem as transformações dos hábitos causadores deste agravo, [...] quando dão a alta eu tentaria buscar algo de que ele gostasse, por exemplo, trabalhar com ele de uma maneira que não fosse imposta, mas trabalhar o emocional dele; vamos trabalhar de uma forma alegre, divertida, talvez grupos de assistência, onde as pessoas podem falar e ouvir as outras. (E2)

Cuidados básicos e específicos, quanto a seus costumes; dieta sempre foca o paciente, é uma forma de a gente fazer o máximo possível para retornar o paciente em uma sociedade, tirar o paciente. Tem que procurar saber primeiro qual éo meio social dele, cuidados básicos, por exemplo, é você fazer com que o paciente tome a sua medicação nos horários certos, que tenha seus bons hábitos, 
alimentação no horário certo, alimentação dele conforme a dieta, fazer com que se torne o mais autônomo possível pra tirar a dependência do paciente. (E3)

Que mantenham o paciente estabilizado na sua doença, desde a prevenção, orientar a família, 0 paciente em casa. (E4)

Os pacientes crônicos necessitam de atenção integrada que envolva tempo, cenários de saúde, cuidadores e treinamento para realizarem seus cuidados em casa, fatores importantes para a qualidade de vida ${ }^{8}$. Dessa forma, o enfermeiro deve comprometer-se com a qualidade de vida do paciente e procurar estratégias que lhe permitam um viver saudável, apesar de ele ter uma doença crônica e necessitar cuidados espećficos, como menciona o $\mathrm{E} 3$.

A educação à saúde é uma das responsabilidades que o enfermeiro, e o seu objetivo básico é desenvolver o conhecimento do paciente na expectativa de que ocorrerá mudança de comportamento, bem como avaliar as necessidades e os desejos de apreensão do paciente e da sua família ${ }^{16}$, mesmo que a palavra utilizada seja orientação nos depoimentos dos sujeitos. Para tal, sugere-se que a educação à saúde agregue intervenções educacionais suplementares com estratégias comportamentais, aumentando a efetividade da intervenção de ensino ${ }^{17}$.

\section{Orientação}

A orientação visa à continuidade do tratamento, e uma das possibilidades de esta ocorrer é oferecida pelo uso dos recursos já existentes na comunidade. Quando o paciente estiver se sentido mal, deverá procurar uma Unidade Básica de Saúde (UBS). Ele também deve conhecer melhor a UBS do seu bairro, não se consultar com um médico ou outro, e sim ter seu médico como referencial. É preciso que faça da UBS uma ponte para o hospital, ou seja, uma via de mão dupla. Isso se observa nas expressões a seguir.

Orientação aos pacientes e familiares durante a internação e na ocasião da alta [...] [...] venha fazer a reconsulta, que não abandone o tratamento, inscrever no Posto de Saúde, nos programas [...]. (E7)

[...] promover a saúde é você dar alternativa; promoção de saúde éusar os recursos já existentes dos gestores atuais, fazer o hospital lá na ponta do bairro, para que ele dê continuidade, uma ponte. (E2)

Aconselhar que quando se sentir mal deve procurar uma Unidade de Saúde [...] conhecer melhor a Unidade Básica de Saúde dele; ele tem sempre o médico dele, que não fique consultando com um médico ou outro, o mesmo médico passa a conhecer a história da doença dele [...] orientar para participação de grupo de hipertensão [...]. (E3)

Orientação com relação à atividade física, alimentação para que ele possa restabelecer $e$ manter as condições físicas em bom estado, que possa ser controlada a doença cardíaca. (E5)

Orientar o paciente que tem uma hipertensão; você tem que estar orientando sobre o que éalimentação, tenha sempre controle, fazer exercícios de forma que o paciente compreenda que consiga fazer, orientar o paciente bem sobre a doença para que não tenha complicações. (E6)

Procurar orientar os pacientes sobre os cuidados que deve ter em casa, como a restrição de sal para pacientes hipertensos, cuidados quanto ao uso de medicamento, para que não interrompa o tratamento. (E8)

0 enfermeiro atua tanto na manutenção como na promoção e recuperação da saúde 9 . Ficou evidente nos depoimentos dos sujeitos deste estudo que o enfermeiro, além de realizar a promoção à saúde por meio da educação, também promove a saúde com determinadas orientações, no sentido de prevenir os sintomas e agravos possíveis: mudanças de hábitos, entre elas preferência por uma alimentação saudável, controle do nível de estresse e atividade física. Com esses cuidados, no sentido de informar, ele oferece condições para que o paciente crônico cardíaco mantenha saúde.

\section{Concepções de saúde}

As concepções de saúde evidenciam duas perspectivas como equilíbrio e conforto/bem-estar. Neste estudo, considera-se equilíbrio o momento em que o ser humano está em plena normalidade com suas dimensões biológica e psíquica; consequentemente, suas necessidades fisiológicas estão satisfeitas. Essa concepção originou-se das falas dos enfermeiros, não havendo similaridades com a definição de Horta ${ }^{9}$, na qual o ser humano, por suas características, é um agente de mudança no universo dinâmico e também a causa de equilíbrio; portanto, encontrar-se com saúde é estar em equilíbrio dinâmico no tempo e no espaço. Essa visão de saúde como equilíbrio é óptica reducionista. Ao definir saúde como equilíbrio, o enfermeiro está consciente da prevenção da doença, como exprime a seguinte fala.

[...] o processo de saúde-doença depende do ponto de vista de quem avalia o que é saúde e o que é doença, [...] não estão juntos; quando você fala em 
saúde, automaticamente está fazendo a prevenção de alguma doença que possa a vir a ter. (E1)

A saúde é quando as necessidades básicas dele estão supridas. (E2)

Saúde é quando o ser humano está com todas as suas faculdades físicas e psíquicas dentro do parâmetro de normalidade, é você estar pleno, não estar com alguma patologia física, psíquica. (E7)

Saúde é qualquer coisa que não esteja irregular, e a doença quando não está dentro do padrão de normalidade. (E8)

A definição dada pelos enfermeiros da pesquisa quanto à perspectiva conforto/bem-estar vai além da definição preconizada pela Organização Mundial da Saúde ${ }^{18}$. Segundo eles, o ser humano tem necessidades básicas que precisam ser satisfeitas e atendidas, como lazer, moradia, profissão. Além disso, ele também necessita ser respeitado em seus direitos. Tudo isso trará, para ele, segurança e conforto pleno, conforme expressam as falas:

Para mim, uma pessoa saudável, além da definição da Organização Mundial de Saúde, é a pessoa que tem todos aqueles requisitos, toda necessidade básica e necessária, tem lazer, tem moradia, profissão, é ter seus direitos de cidadãos. (E1)

É tudo que traz um confor to pessoal para gente, se você está bem com o mundo, com você mesmo, com a familia e com o social, isso é saúde. Saúde é o bem-estar social, físico e mental. (E3)

Saúde é o bem-estar físico, social, psíquico de toda pessoa. (E4)

Saúde é o bem-estar geral, tanto físico como psíquico. (E8)

Tais situações demonstram corroborar que a saúde é um processo contínuo, com estados situacionais dinâmicos e subjetivos, que permite ao ser humano o funcionamento nos seus papéis, com prazer ${ }^{18: 14}$. Em 1946, quando a Organização Mundial da Saúde definiu a saúde como um estado de completo bem-estar físico, mental e social, e não apenas a mera ausência da doença, já projetava esse conceito para o futuro. Entretanto, tal conceito permanece até a atualidade como utópico, devido às dificuldades de se definir e mensurar o bem-estar ${ }^{18: 11}$.

\section{Concepções de doença crônica cardíaca}

Evidenciam-se, nos depoimentos dos enfermeiros, duas perspectivas relevantes da sua prática profissional relacionada à concepção de doença crônica cardíaca, o desequilíbrio e a incapacidade. A perspectiva desequilíbrio acontece quando as necessidades básicas do ser humano não estão em harmonia, o que prejudica suas atividades cotidianas. Nesse caso, cita-se a doença como uma situação em que o ser humano não está bem; está fora do padrão de normalidade nas dimensões biopsíquica, como se observa nos relatos a seguir:

[...] de não conseguir exercer mais suas atividades no dia-a-dia; a doença é estar em desequilíbrio, [...] a ponto de não se conseguir manter as atividades e rotinas do padrão preconizado pela sociedade, para mim éisso. (E1)

É o estado em que o indivíduo gera desequilibrio em suas necessidades básicas levando-o ao adoecimento físico, mental ou psíquico, ele está doente, ele produziu desequilíbrio [...] a doença significa que há um desequilíbrio numa dessas necessidades básicas que ele tem. (E2)

Doença é qualquer coisa que esteja fora do padrão de normalidade, inadequadamente, tanto mental como física. (E8)

0 desequilíbrio gera no ser humano necessidades que se caracterizam por estados de tensão, conscientes ou inconscientes, que o levam a buscar a satisfação de tais necessidades para recuperar seu equilíbrio dinâmico no tempo e no espaço ${ }^{9}$.

0 aspecto incapacidade caracteriza-se por tudo aquilo que perturba a tranquilidade do ser humano nas suas dimensões biopsicossocioespirituais e prejudica o estar consigo mesmo em sua plenitude e na sua totalidade, como vem explicitado a seguir:

A doença é aquilo que perturba o sossego, altera sua vida tanto no físico como no mental. (E3)

A doença já seria instalada; a patologia não é necessariamente física, é até mais psicológica, psíquica, no caso, a depressão, o que acarreta mais do que a própria doença física. (E4)

Qualquer problema físico, mental, espiritual ou até social acarreta uma doença. (E5)

A doença é tudo aquilo que incomoda, tudo o que está incomodando, seja físico, mental, espiritual; como as pessoas falam, aquilo que está te incomodando, para mim. (E6) 
A doença ocorre quando as necessidades não são atendidas ou quando são atendidas inadequadamente, trazem desconforto e se prolongam. É também considerada um fenômeno orgânico, redutível a processos físicos-químicos ${ }^{9: 18}$.

\section{Ambiente}

Nas falas dos enfermeiros entrevistados, o ambiente é considerado um lugar ou local onde se vive e se trabalha, relaciona-se em condições de bem-estar. Também é considerado ambiente o local onde se está inserido, em relação ao planeta, como se observa a seguir:

Ambiente é o local onde você está inserido e, no caso, em relação ao Planeta, mas pode ser o meu trabalho, a minha vida, a minha casa [...] é o ambiente, é o local onde o homem está inserido.

Local em que vivem todos os seres humanos em comunidades é o ambiente, é tudo, é o que existe no mundo todo [...]. (E4)

O ambiente é onde você vive, onde você trabalha, por onde você circula [...]. (E7)

Quando o ser humano cria socialmente um ambiente onde vive salutarmente, ele cria espaços de possibilidades e impossibilidades que estão articulados ao processo psíquico e que mantêm as pessoas em movimento, unindo-as para as questões que lhes interessam e lhes satisfaçam. 0 ambiente consiste no que é interno e externo ao ser humano, fatores que, embora formem um processo único, nem sempre são harmônicos, apesar de não viverem em conflito ${ }^{9}$.

Outra perspectiva é o ambiente em construção. 0 ser humano vai construindo-o, seja no trabalho, na sua residência ou no lazer. Esse ambiente poderá influenciá-lo ou não, e, consequentemente, haverá uma transformação, gradativa em seu espaço social. Observa-se a fala:

Ambiente você constrói. [...] o ambiente você cria,
você tem uma influência nele ou não [...]. (E3)

Percebe-se que o depoimento do enfermeiro vem ao encontro da literatura pesquisada, que afirma que entre 0 ambiente e o ser humano há uma inseparabilidade, e, como as mudanças sequenciais do ciclo vital são contínuas, ocorrem de forma constante revisões da interação entre eles ${ }^{9}$. Todos os ambientes, sejam físicos, administrativos, sociais, tecnológicos, são considerados organizacionais e estão relacionados, devendo contribuir para as relaç̃es de cuidado?

\section{CONCLUSÕES}

Os enfermeiros deste estudo utilizam vários modelos teóricos de enfermagem dos mais diversos paradigmas, demonstrando a carência de uma filosofia institucional que forneça base para o processo de cuidar, a partir de um modelo filosófico metodológico do cuidado e de uma dimensão epistemológica. No entanto, nem por isso, o enfermeiro deixa de ter um papel relevante no seu trabalho pelas valorações das ações de cuidado apresentadas.

A Enfermagem é ciência, arte e profissão, pois o enfermeiro utiliza-se de conhecimento específico e de outros saberes que ancoram o desenvolvimento de raciocínios, julgamentos clínicos, tomadas de decisões, sensibilidades e profissionalismo, para que consiga sustentar com argumentos consistentes suas decisões e ações aos seus pares e à equipe de saúde. Enfim, a prática do cuidado é manifestada pelo enfermeiro com significativa importância, mediante ação efetiva, humana, calcada em conhecimentos específicos, visto que é oferecida aos doentes, seres integrados e integradores, ativos e com sentimentos.

Os enfermeiros desenvolvem o processo de cuidar por meio das ações nas dimensões técnicas e expressivas, durante a visita diária de enfermagem. Tais dimensões não ocorrem isoladamente, mas cada qual tem sua magnitude, dependendo de como acontece a interação/vínculo entre profissional e paciente.

Diante disso, o profissional precisa ser visível perante a equipe de enfermagem, de saúde e da sociedade, como coadjuvante do processo de cuidar desses pacientes. Deve também buscar no seu caminhar profissional, seja na prática, no ensino ou na pesquisa, todos os dias, "um saber, um fazer e um ser enfermagem", com conhecimento, compreensão, empatia, envolvimento, proximidade, solidariedade e dignidade, em todas as dimensões do ser humano, como um agente inovador, moderador e transformador do processo de cuidar, propiciando ao paciente empoderamento a fim de mudança no estilo de vida.

Esta pesquisa indica novos percursos para avaliações do desenvolvimento do processo de cuidar e da sua representação na equipe de enfermagem.

\section{Referências}

1.Conselho Internacional de Enfermagem-CIE. Classificação internacional para a prática de enfermagem beta 2. Traduzido por de Heimar de Fátima São Paulo (SP): Cenfobs; 2003.

2.Waldow VR. Cuidar expressão humanizadora da enfermagem. Petrópolis (RJ): Vozes; 2006.

3.Atkinson LD, Murray ME. Fundamentos de enfermagem: introdução ao processo de enfermagem. Rio de Janeiro (RJ): Guanabara; 1989.

4.Organização Mundial de Saúde-OMS. Cuidados inovadores para condições crônicas: componentes estruturais de ação. Relatório Mundial. Braślia (DF); 2003. 
5.Bardin L. Análise de conteúdo. Lisboa (P0): Ed. 70; 1977.

6.Araújo S, Araújo IEM. Princípios básicos de fisiologia cardiocirculatória. In: Araújo CE, Nishide VM, Nunes WA, organizadoras. Assistência de enfermagem ao paciente gravemente enfermo. São Paulo (SP): Atheneu; 2003. p.201-22.

7.Teixeira RC, Lacerda MR, Mantovani MF. A dimensão expressiva do cuidado em domicílio: um despertar a partir da prática docente. Curitiba (PR); 2007. Apresentado na vivência da prática de docência do Curso de Pós - graduação em enfermagem da Universidade Federal do Paraná.

8.Cavalcanti ACD, Coelho MJ. A linguagem como ferramenta do cuidado do enfermeiro em cirurgia cardíaca. Esc Anna Nery Rev Enferm 2007 jun; 11 (2): 220-26.

9.Horta WA. Processo de enfermagem. São Paulo (SP): EPU; 2005.

10.Bobroff MCC. Identificação de comportamento de cuidado afetivoexpressivo no aluno de enfermagem: construção de instrumento. [dissertação de mestrado] Ribeirão Preto (SP): Escola de Enfermagem de Ribeirão Preto/ USP; 2003.

11.Passos ES. De anjos a mulheres: ideologias e valores na formação de enfermeiros. Salvador(BA): EDUFBA/EGBA; 1996.
12.Conselho Federal de Enfermagem- CFE. Documentos básicos. Natal (RN); 2002.

13. Costenaro RGS, Lacerda MR. Quem cuida de quem cuida? Quem cuida do cuidado? $2^{\mathrm{a}}$ ed. Santa Maria (RS): Unifra; 2002.

14.Cianciarullo TI, Gualda DMR, Melleiro MM, Anabuki MH, organizadoras. Sistema de assistência de enfermagem: evolução e tendências. São Paulo (SP): Ícone; 2001.

15.Ministério da Saúde (BR). Política nacional de promoção da saúde. Brasília (DF); 2006. [on-line] [citado 15 jun 2007]. Disponível em: http://portal.saude.gov.br/portal/arquivos/pdf/ portaria687_2006_anexo1.pdf.

16. Rocha KPWF. A educação em saúde no ambiente hospitalar. Nurs 2007 maio; 108 (9): 216-21.

17.Woods SL, Froelicher ESS, Motzer SAU. Enfermagem em cardiologia. Tradução de Shizuka Ishii. Barueri (SP): Manole; 2005.

18 - Mioto RCT. Do conhecimento que temos à integração que fazemos: uma reflexão sobre atenção às famílias no âmbito das políticas sociais. In: Althoff CR, Elsen I, Nitschke RG, organizadoras. Pesquisando a família olhares contemporâneos. Florianópolis (SC): Papa-Livro; 2004. p.07-114. 